\title{
Hard Palate Melanoma: A Population-based Analysis of Epidemiology and Survival Outcomes
}

\author{
CARLO M. ORANGES ${ }^{1}$, GIOVANNI SISTI ${ }^{2}$, DIMITRIOS NASIOUDIS ${ }^{3}$, MATHIAS TREMP ${ }^{1}$, \\ PIETRO G. DI SUMMA ${ }^{4}$, DANIEL F. KALBERMATTEN ${ }^{1}$, RENÉ D. LARGO ${ }^{5}$ and DIRK J. SCHAEFER ${ }^{1}$ \\ ${ }^{1}$ Department of Plastic, Reconstructive, Aesthetic, and Hand Surgery, \\ Basel University Hospital, University of Basel, Basel, Switzerland; \\ ${ }^{2}$ Department of Obstetrics and Gynecology, Lincoln Medical Center, New York, NY, U.S.A.; \\ ${ }^{3}$ Department of Obstetrics and Gynecology, Hospital of the University of Pennsylvania, Philadelphia, PA, U.S.A.; \\ ${ }^{4}$ Department of Plastic, Reconstructive and Aesthetic Surgery, \\ Lausanne University Hospital, Lausanne, Switzerland; \\ ${ }^{5}$ Department of Plastic Surgery, The University of Texas M.D. Anderson Cancer Center, Houston, TX, U.S.A.
}

\begin{abstract}
Background/Aim: Hard palate melanoma is an extremely rare and aggressive tumor arising from the mucosal epithelium of the oral cavity. The aim of this study was to analyze epidemiology, loco-regional treatment patterns and survival outcomes of this disease. Materials and Methods: The National Cancer Institute's Surveillance Epidemiology and End Results (SEER) database was searched for all cases of hard palate melanoma diagnosed between 1973 and 2012. The Kaplan-Meier method was used to calculate overall survival rate, log-rank test to compare survivals of different subgroups, and Cox hazard regression analysis to determine independent predictors of overall survival. Results: Overall, 83 patients were identified, 49 female and 34 males. The distribution among ages was: $13.3 \%<50$ years, $38.6 \%$ between 50 and 69 years, $48.2 \% \geq 70$. Surgery alone was applied in $48.2 \%$ of patients, radiation therapy alone in $6 \%$, and combination of surgery and radiation therapy in 33.7\%. Overall 5-year survival was $26.3 \%$. Survival with adjuvant radiation therapy was not longer than with surgery alone. Conclusion:
\end{abstract}

This work has been presented at the 5th European Association of Plastic Surgeons (EURAPS) Research Council - Joint Meeting with the 8th European Plastic Surgery Research Council (EPSRC), in Brussels, Belgium, May 25th through 26th, 2016.

Correspondence to: Carlo M. Oranges, MD, Department of Plastic, Reconstructive, Aesthetic, and Hand Surgery, Basel University Hospital, Spitalstrasse 21, 4031 Basel, Switzerland. Tel: +41 612652525, Fax: +41 612657301, e-mail: carlo.oranges@usb.ch

Key Words: Head and neck cancer, oral cancer, hard palate, mucosal melanoma, metastasis, treatment, prognostic factors, survival rates, SEER.
Hard palate melanoma is a rare malignancy mostly affecting the elderly, with low overall survival. The main treatment is surgical resection, while adjuvant radiotherapy does not improve survival. The establishment of an international registry is warranted to better define treatment options.

Primary oral melanoma is known to be an extremely rare and aggressive tumor arising from the mucosal epithelium of the oral cavity (1-5). The etiology and pathogenesis are poorly understood and, in contrast to the squamous cell oral carcinoma, no intraoral risk factors have been recognized to date (1-5). Incidence rates are not clearly identified in the literature but primary oral melanomas are reported to account for $0.2-8 \%$ of all melanomas in Europe and in the United States (6-8). Reports are mainly based on isolate or relatively small series of cases $(2,5-11)$.

The unusual primary site and the lack of early warning symptoms explain the advanced presenting stage of this tumor and the poor prognosis. The overall 5-year survival of primary oral mucosal melanoma is reported to be $15 \%$ (7). In early series that used mostly surgery alone the 5-year disease-specific survival rate of head and neck mucosal melanoma varied from $4.5-27 \%$ (12). The majority of mucosal oral melanoma occur in the hard palate (13), and even if the high frequency of this location has been confirmed by recent literature reviews and case series (14, $15)$, to date there is no clinical and histopathological explanation for this specific tumor site predilection.

Surprisingly, the epidemiological characteristics in terms of disease presentation and survival of this tumor subtype specifically occurring in the hard palate have never been studied in a comprehensive manner.

Our main goal was to analyze epidemiological and locoregional treatment patterns and survival outcomes of primary 
oral melanoma occurring in the hard palate in the United States, between 1973 and 2012, using the Surveillance, Epidemiology, and End Results (SEER) population-based registry of the National Cancer Institute. The SEER program is recognized as the most authoritative source of information on cancer incidence and survival in the United States (16). Data are updated annually, undergo vigorous quality control and are available to the public for research purposes.

\section{Materials and Methods}

A cohort of patients derived from the National Cancer Institute SEER database was analyzed. The study included 18 cancer registries as released on November 2014, which cover approximately $28 \%$ of the total US population based on the 2010 census (17). All patient data were de-identified hence there was no need for approval by an institutional review board.

Only cases of invasive primary hard palate melanoma diagnosed between 1973 and 2012 were included in the study. Eligible cases were identified using the codes of the International Classification of Oncology (ICD-O-3/WHO 2008) for tumor morphology $($ melanoma $=8720-8790)$ and topographic location in the hard palate (C05.0-hard palate).

Using the "case-listing" option, demographic (age at diagnosis, race, marital status and year and geographic area of residency at diagnosis) and clinicopathological (historic stage, histological subtype, details of cancer-specific treatment, and survival in months) information were extracted for each case. SEER has standardized and simplified staging to ensure consistent definitions over time, defined as follows: localized cancer, when the disease is limited to the organ in which it began, without evidence of spread; regional cancer, when the disease has spread beyond the primary site to nearby lymph nodes or organs and tissues; distant cancer, when the disease has spread from the primary site to distant organs or distant lymph nodes; unstaged cancer, for those cases without enough information to indicate a stage.

The patients were categorized according to the geographic area of residence within the United States at the time of diagnosis: central (Detroit, Iowa, Kentucky, Louisiana, and Utah), eastern (Connecticut, New Jersey, Atlanta, rural Georgia) and western (Alaska, California, Hawaii, Los Angeles, New Mexico, San Francisco, San Jose, and Seattle).

In our cohort overall survival rate was determined using the Kaplan-Meier method. Subjects were assumed alive at the time of study cut-off (December 31st, 2012). In the SEER database, survival is calculated as the number of months between the date of cancer diagnosis and the date of death. The log-rank test was employed in order to compare overall survival between different subgroups. In addition, a Cox hazard regression analysis was performed in an attempt to determine independent predictors of overall survival.

Statistical analysis was performed with SPSS version 22 statistical package. Statistical significance was set at 0.05 for alpha level and all $p$-values were two-sided.

\section{Results}

A total of 83 cases of hard palate melanoma diagnosed between 1973 and 2012 were identified. The majority of
Table I. Demographic and clinicopathological characteristics of HPM patients.

n $(\%)$

\begin{tabular}{|c|c|}
\hline \multicolumn{2}{|l|}{ Age at diagnosis } \\
\hline$<50$ & $11(13.3)$ \\
\hline $50-69$ & $32(38.6)$ \\
\hline$\geq 70$ & $40(48.2)$ \\
\hline \multicolumn{2}{|l|}{ Race } \\
\hline White & $60(72.3)$ \\
\hline Black & $7(8.4)$ \\
\hline Other & $16(19.3)$ \\
\hline \multicolumn{2}{|l|}{ Gender } \\
\hline Male & $34(41.0)$ \\
\hline Female & $49(59.0)$ \\
\hline \multicolumn{2}{|l|}{ Marital status } \\
\hline Married & $41(49.4)$ \\
\hline Unmarried & $35(42.2)$ \\
\hline Unknown & $7(8.4)$ \\
\hline \multicolumn{2}{|l|}{ SEER Registry } \\
\hline Western & $45(54.2)$ \\
\hline Eastern & $17(20.5)$ \\
\hline Central & $21(25.3)$ \\
\hline \multicolumn{2}{|l|}{ Year of diagnosis } \\
\hline 1973-1982 & $9(10.8)$ \\
\hline 1983-1992 & $11(13.3)$ \\
\hline $1993-2002$ & $16(19.3)$ \\
\hline 2003-2012 & $47(56.6)$ \\
\hline \multicolumn{2}{|l|}{ Stage } \\
\hline Localized & $37(44.6)$ \\
\hline Regional & $27(32.5)$ \\
\hline Distant & $11(13.3)$ \\
\hline Unstaged & $8(9.6)$ \\
\hline \multicolumn{2}{|l|}{ Treatment } \\
\hline No surgery or radiation & $10(12.0)$ \\
\hline Surgery only & $40(48.2)$ \\
\hline Surgery and Radiation & $28(33.7)$ \\
\hline Only radiation & $5(6.0)$ \\
\hline \multicolumn{2}{|l|}{ Reason for no surgery } \\
\hline Not recommended & $12(14.5)$ \\
\hline Recommended but not performed, patient refused & $2(2.4)$ \\
\hline Recommended but not performed, unknown reason & $1(1.2)$ \\
\hline \multicolumn{2}{|l|}{ Diagnosis } \\
\hline 8720/3: Malignant melanoma, NOS & $52(62.7)$ \\
\hline 8746/3: Mucosal lentiginous melanoma & $7(8.4)$ \\
\hline 8721/3: Nodular melanoma & $5(6.0)$ \\
\hline 8772/3: Spindle cell melanoma, NOS & $5(6.0)$ \\
\hline 8743/3: Superficial spreading melanoma & $4(4.8)$ \\
\hline 8730/3: Amelanotic melanoma & $3(3.6)$ \\
\hline 8744/3: Acral lentiginous melanoma, malignant & $3(3.6)$ \\
\hline 8742/3: Lentigo malignant melanoma & $1(1.2)$ \\
\hline 8745/3: Desmoplastic melanoma, malignant & $1(1.2)$ \\
\hline 8770/3: Mixed epithelioid and spindle cell melanoma & $1(1.2)$ \\
\hline 8771/3: Epithelioid cell melanoma & $1(1.2)$ \\
\hline
\end{tabular}

these cases $(n=47,56.6 \%)$ were diagnosed between 2003 and 2012. The general demographic and clinicopathological characteristics of our cohort are listed in Table I. 


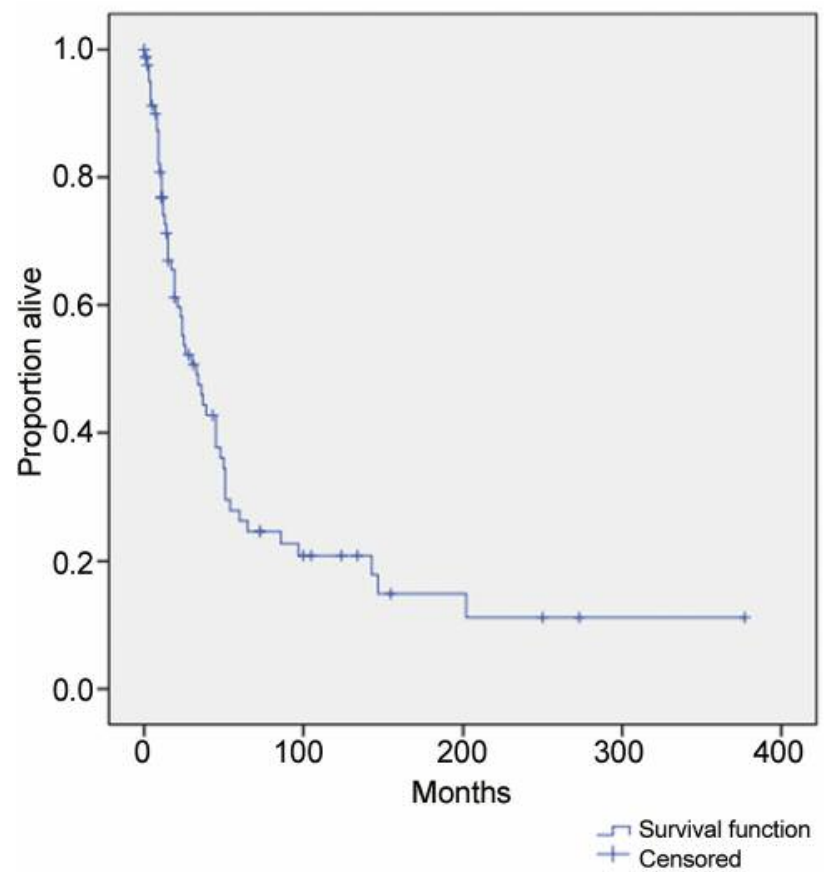

Figure 1. Kaplan-Meier analysis: overall observed survival.

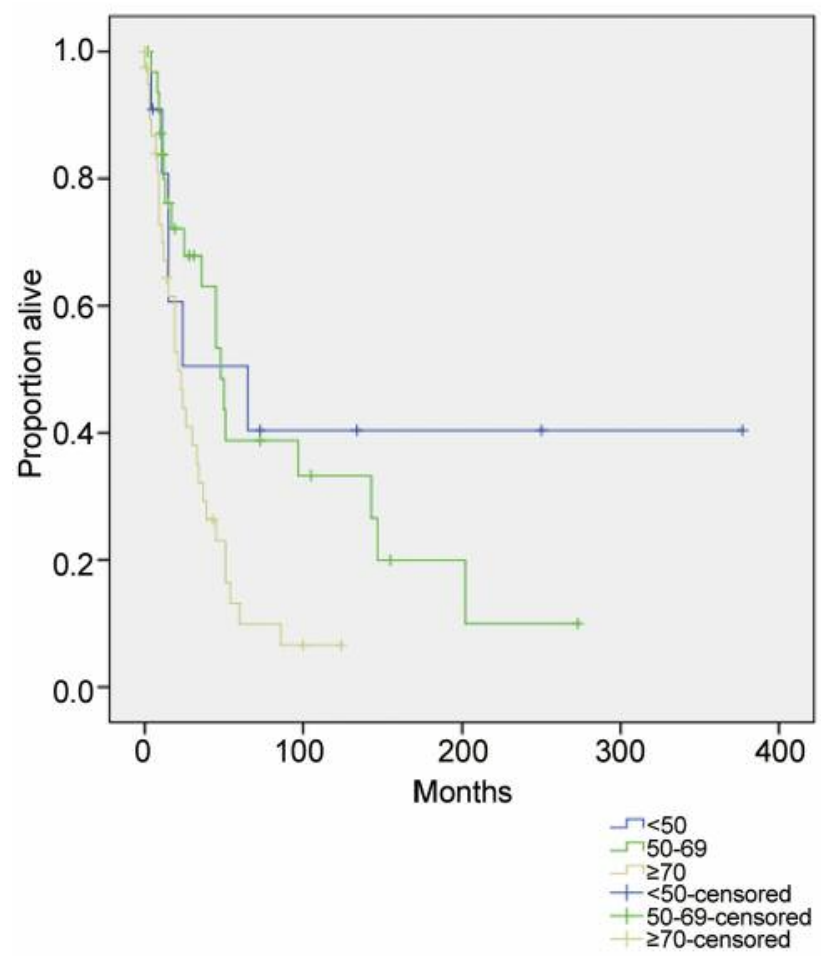

Figure 2. Kaplan-Meier analysis: observed survival of patients with hard palate melanoma stratified by age.

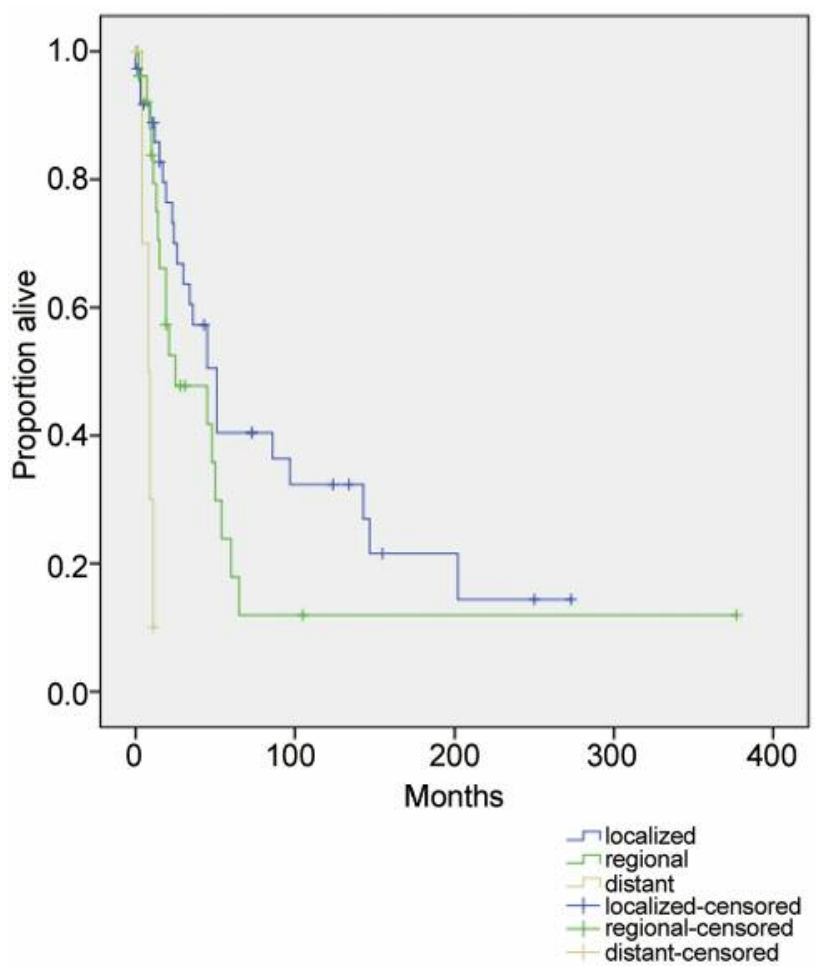

Figure 3. Kaplan-Meier analysis: observed survival of patients with hard palate melanoma stratified by stage.

The age at diagnosis ranged between 26 and 87 years with a mean of 66 , distributed among the study population as follows: $13.3 \%<50$ years, $38.6 \% 50-69$ years, $48.2 \%$ $>70$ years. Males represented $41 \%$ of the cases and females 59\%. The cohort included 60 withe patients (72.3\%), 7 black patients (8.4\%), and 16 patients $(19,3 \%)$ classified as "other" (including American Indian/Alaska Native and Asian/Pacific Islander), with a white/black ratio of $8.6: 1$.

The most frequent histology was malignant melanomas (8720/3), that occurred in 52 patients $(62.7 \%)$, followed by mucosal lentiginous melanoma $(n=7,8.4 \%)$. Patients presented with the following stages at diagnosis: localized in $44.6 \%$, regional in $32.5 \%$, distant in $13.3 \%$, unstaged in 9.6\%. Surgery alone was performed in 40 patients (48.2\%), recommended but not performed in 2 patients $(2.4 \%)$ and not performed and not recommended in 12 patients $(14.2 \%)$. Radiation therapy alone was performed in 5 cases $(6 \%)$. The combination of surgery and radiation therapy was performed in 28 patients (33.7\%). In total, surgery was performed in $81.9 \%$ of patients, and when it was not performed the reasons were: not recommended (14.5\%), recommended but not performed due to patient refusal (2.4\%), and recommended, but not performed for unknown reason $(1.2 \%)$. 


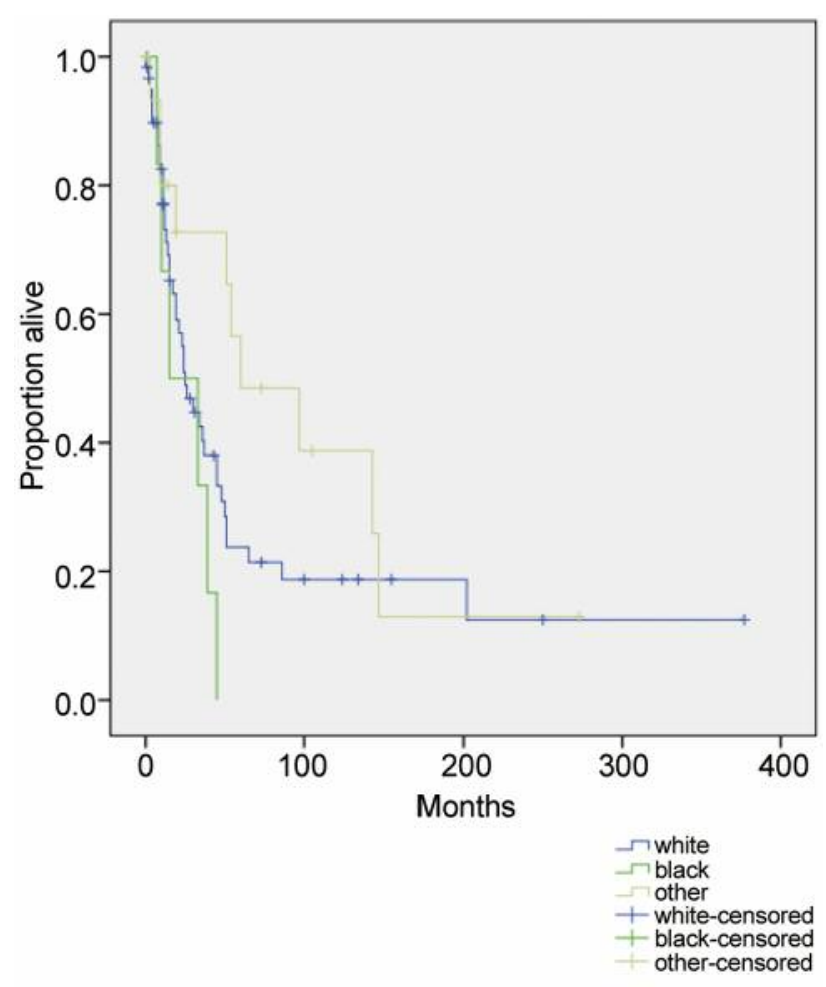

Figure 4. Kaplan-Meier analysis: observed survival of patients with hard palate melanoma stratified by race.

There was a linear direct increase in incidence along the decades: $10.8 \%$ of diagnoses were made during the decade $1973-1982,13.3 \%$ during the decade 1983-1992, 19.3\% during the decade $1993-2002$, and $56.6 \%$ during the decade 2003-2012.

Survival analysis (Figure 1) revealed that overall 5-year survival rate in patients with hard palate melanoma was $26.3 \%$ (74\% at 1 year, $59 \%$ at 2 year, $45.9 \%$ at 3 year, $36.2 \%$ at 4 year). Patients with an age below 50 years had a median survival of 65 months $(95 \% \mathrm{CI}=0-140.4)$, for patients between 50 and 69 it was 48 months $(95 \% \mathrm{CI}=33.3-62.7)$, and 21 months $(95 \% \mathrm{CI}=12.5-29.5)$ for patients of age equal or over 70 years (Figure 2). Survival of patients aged between 50 and 69 years was significantly higher than that of patients aged equal or over 70 (log-rank, $p=0.006$ ), while the higher survival of patients below 50 was not found to be significant (log-rank, $p=0.053)$.

Median survival of patients with localized disease was 51 months $(95 \% \mathrm{CI}=35.6-66.4), 25$ months for patients with regional disease $(95 \% \mathrm{CI}=0-59.7)$, and 8 months for patients with distant disease $(95 \% \mathrm{CI}=4.1-11.9)$, as shown in Figure 3 . The advantage in terms of survival observed in patients with localized or regional disease in comparison with

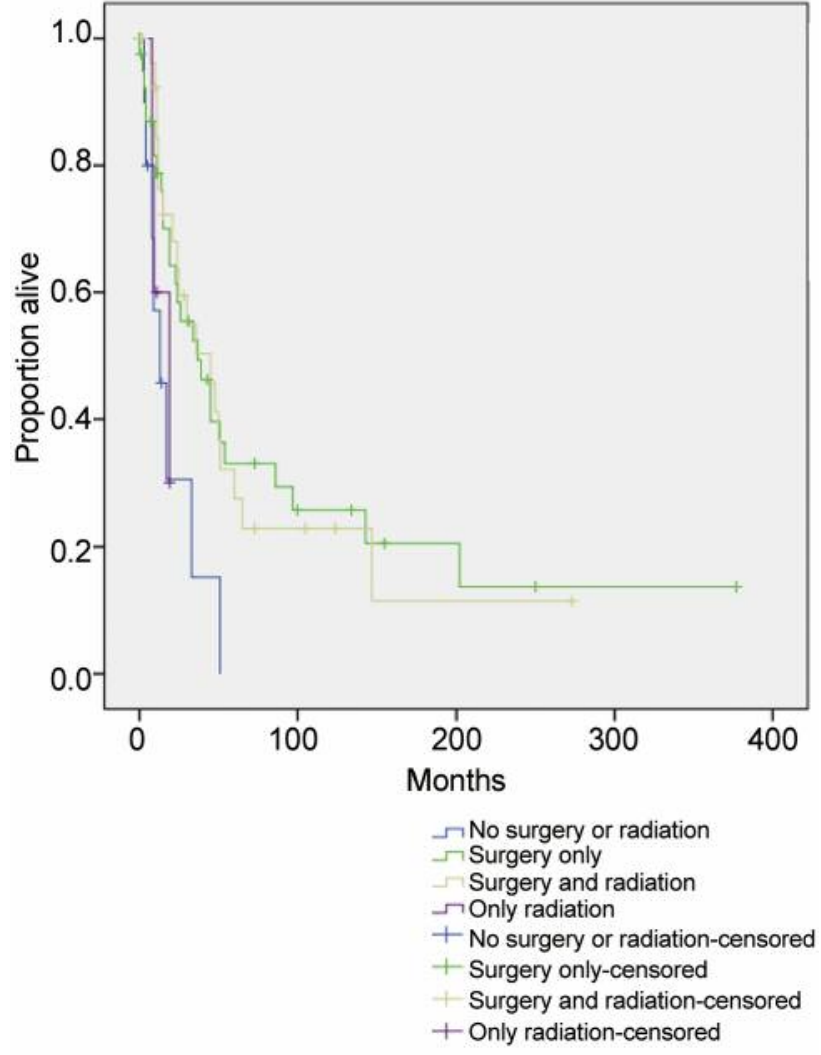

Figure 5. Kaplan-Meier analysis: observed survival of patients with hard palate melanoma stratified by treatment.

patients with distant disease was statistically significant (logrank, $p<0.001)$. Instead, the difference in terms of survival between patients with regional and localized disease was not statistically significant (log-rank, $p>0.05$ ).

Regarding differences among racial groups, Kaplan-Meier survival analysis revealed a median survival equal to 25 months $(95 \% \mathrm{CI}=15.7-34.3)$ for white patients, 15 months $(95 \% \mathrm{CI}=0-42.6)$ for black, and 60 months $(95 \% \mathrm{CI}=0-125.5)$ for other (Figure 4). Survival of black patients was significantly lower than that of other (log rank, $p=0.007)$.

With reference to different treatment options (Figure 5), a median survival of 13 months $(95 \% \mathrm{CI}=3.2-22.8)$ was observed for patients not receiving surgery or radiation, 37 months (95\% CI=17-57) for patients undergoing surgery only, 45 months $(95 \% \mathrm{CI}=19.6-70.4)$ in cases of surgery and radiation, and 19 months $(95 \% \mathrm{CI}=3.4-34.6)$ in cases of radiation only. The group receiving no surgery or radiation had a significantly lower survival than the groups receiving surgery only (log-rank, $p=0.019$ ) or surgery and radiation (log-rank, $p=0.015$ ), while the difference was not significant in comparison with the group receiving radiation only (logrank, $p=0.72$ ). There were no other differences statistically significant for the following comparisons: patients 
undergoing surgery only versus patients undergoing surgery and radiation (log-rank, $p=0.96$ ), patients undergoing surgery only versus patients undergoing radiation only (log-rank, $p=0.237$ ), patients undergoing surgery and radiation versus patients undergoing radiation only (log-rank, $p=0.071)$.

Cox regression multivariate analysis (Table II) revealed that independent predictors of cancer-specific survival (poorer prognosis) were stage with distant disease, white race, and age over 70. Although not statistically significant, surgery only and radiation only were close to conferee an advantage in comparison to the combination of surgery and radiation (log-rank, $p=0.053)$.

\section{Discussion}

Primary mucosal melanomas are extremely rare and biologically aggressive malignancies involving several anatomic districts: the head and neck (55.4\% of the cases), the female genital tract $(18 \%)$, the anal/rectal tract $(23.8 \%)$, and the urinary tract $(2.8 \%)(18)$. Overall, this variant of melanoma represents about $1.4 \%$ of all melanomas, in opposition to the cutaneous form which is estimated to be the fifth most common cancer in the United States among men, and the sixth among women (19-21). Previous reports have also indicated that incidence of mucosal melanoma is believed to remain stable while the incidence of cutaneous melanoma is growing $(19,22,23)$. However, our research found a linear increase in the incidence of hard palate melanoma along the decades, with a peak in the decade 2003-2012.

With reference to the oral cavity, mucosal melanoma represents $1-2 \%$ of all malignancies, and is predominantly localized in the hard palate and maxillary alveolus $(13,24)$. In addition, the pathogenesis remains unclear, with mechanical trauma including injury from ill-fitting prostheses, infection, and tobacco use cited as possible causative factors $(24,25)$.

Importantly, increased expression of bcl-2, p53 and loss of p16 expression were reported as frequent and early events in the mucosal melanoma of the oral cavity, indicating that dysregulation of the $\mathrm{G}_{1} / \mathrm{S}$ phase and impairment of programmed cell death may play a pathogenic role $(24,26)$.

Our research investigated epidemiology and survival outcomes of the mucosal melanoma localized in the hard palate. Indeed, despite its relevance in the context of oral mucosal melanomas, previous data are limited to several small single-institutional series or case reports, or are only partially included in papers that used a large US cohort to perform a global analysis of mucosal melanomas of the head and neck without a specific focus in this anatomical site $(27,28)$.

To this end, we used the SEER Program registries that collect data on patient demographics, primary tumor site, tumor morphology, stage at diagnosis, first course of treatment, and follow-up for vital status (16). The SEER Program is the most authoritative and comprehensive source
Table II. Multivariate Cox regression analysis for predictors of cancerspecific survival.

\begin{tabular}{|c|c|c|c|c|c|}
\hline & \multirow[b]{2}{*}{ B } & \multirow[b]{2}{*}{ Sig. } & \multirow[b]{2}{*}{$\operatorname{Exp}(B)$} & \multicolumn{2}{|c|}{$95 \% \mathrm{CI}$ for $\operatorname{Exp}(\mathrm{B})$} \\
\hline & & & & Lower & Upper \\
\hline \multicolumn{6}{|l|}{ Stage } \\
\hline Localized & & 0.000 & & & \\
\hline Regional & 0.472 & 0.251 & 1.604 & 0.717 & 3.589 \\
\hline Distant & 2.963 & 0.000 & 19.365 & 5.316 & 70.542 \\
\hline Unstaged & -0.484 & 0.424 & 0.616 & 0.188 & 2.021 \\
\hline \multicolumn{6}{|l|}{ Race } \\
\hline White & & 0.010 & & & \\
\hline Black & 0.809 & 0.184 & 2.246 & 0.680 & 7.420 \\
\hline Other & -1.072 & 0.019 & 0.342 & 0.139 & 0.840 \\
\hline \multicolumn{6}{|l|}{ Year of diagnosis } \\
\hline 1973-1982 & & 0.302 & & & \\
\hline 1983-1992 & -0.445 & 0.454 & 0.641 & 0.200 & 2.053 \\
\hline $1993-2002$ & -1.092 & 0.081 & 0.336 & 0.099 & 1.143 \\
\hline $2003-2012$ & -0.385 & 0.455 & 0.680 & 0.248 & 1.868 \\
\hline \multicolumn{6}{|l|}{ Marital status } \\
\hline Married & & 0.267 & & & \\
\hline Umarried & 0.591 & 0.141 & 1.806 & 0.822 & 3.968 \\
\hline Unknown & 0.581 & 0.295 & 1.788 & 0.603 & 5.306 \\
\hline \multicolumn{6}{|l|}{ Age at diagnosis } \\
\hline$<50$ & & 0.003 & & & \\
\hline $50-69$ & 0.401 & 0.470 & 1.493 & 0.503 & 4.428 \\
\hline$\geq 70$ & 1.451 & 0.007 & 4.269 & 1.479 & 12.326 \\
\hline \multicolumn{6}{|l|}{ Treatment } \\
\hline No surgery or radiation & & 0.053 & & & \\
\hline Surgery only & -1.458 & 0.018 & 0.233 & 0.070 & 0.777 \\
\hline Surgery and Radiation & -0.840 & 0.154 & 0.432 & 0.136 & 1.371 \\
\hline Only radiation & -1.670 & 0.045 & 0.188 & 0.037 & 0.960 \\
\hline
\end{tabular}

Bold prints, $p<0.05$.

of information on cancer incidence and survival, covering approximately one third of the US population (16).

Outcomes of 83 patients from the SEER Program were analyzed. The mean age of our study population was 66 years. Although there was a wide range from 26 to 87 years, only $13.3 \%$ of patients presented age at diagnosis below 50 and $48.2 \%$ was over 70 , consistent with previous reports showing that this disease affects adults of all ages but is most common in the elderly population $(13,27,29,30)$. We found a female preponderance, in line with previous researches $(7$, 31 ), but in contrast with others who found male preponderance or no difference in the incidence of this tumor $(28,32-34)$. According to previous research, we also found a relatively higher incidence in the ethnic group designated as "others", which also included Asians (7, 10, 24, 35, 36). Interestingly, white race was an independent adverse prognostic factor for survival. The overall survival at 5 years in our SEER cohort was $26.3 \%$, consistent with the rate of $25.2 \%$ reported by a previous population-based analysis that included all mucosal melanomas of the head and neck (27). 
Previous investigations have highlighted the importance of an early-stage diagnosis. Our research further supports these indications as it shows a significantly better survival for patients diagnosed with a localized or regional disease in comparison with distant disease. Cox regression multivariate analysis also indicated that the stage with distant disease is an independent predictor of lower cancerspecific survival. Delays in the diagnosis can be caused by the limited accessibility of the lesion with a dermoscope (24). Moreover, it was observed that approximately one third of oral melanomas are amelanotic, although in our cohort this subtype represented only $3.6 \%$ of all diagnoses $(18,37)$. However, according to our data, dermatologists are urged to be aware of the risk of hard palate melanoma and oral mucosal melanoma in general and include inspection of the oral cavity in regular melanoma checkups $(18,24,27)$.

With reference to the different treatment options, the general consensus is to perform complete surgical excision of the primary site, followed by postoperative radiation therapy to treat microscopic or macroscopic residual disease or nodal involvement (18). This is in line with what was observed in our cohort, where surgery alone or the combination of surgery and radiation therapy ensured a significantly better survival than no treatment. Instead, treatment including radiation therapy alone did not conferred a significant improvement, confirming that this tumor shows unresponsiveness to conventional radiation therapy because of a high capacity for sublethal damage repair $(18,38)$.

Finally, according to Cox regression multivariate analysis, age over 70 was an independent predictor of poorer survival in our SEER cohort. This confirmed previous data reported by Jethanamest et al. (27), who also indicated age over 70 as predictor of worst survival, and partially confirmed the data reported by Sun et al. (33), who instead indicated an age over 55 as a cut-off. Conversely, our findings are in contrast with those reported by Wushou et al., who indicated an age of 60 years or younger as an independent adverse prognostic factor for overall survival (14).

\section{Conclusion}

This population-based analysis has reported epidemiology and survival outcomes of patients with hard palate melanoma in the largest cohort systematically examined to date. The 5-year overall survival, equal to $26.3 \%$, confirmed that the prognosis for this disease remains poor. Stage, age and race were identified as independent predictors of cancer-specific survival. Best treatment options were confirmed to be surgery or the combination of surgery and radiation therapy. However, the establishment of an international registry will be helpful in better defining treatment options.

\section{Conflicts of Interest}

The Authors have no conflicts of interest to disclose.

\section{References}

1 Oranges CM, Largo RD, Sisti G, Nasioudis D and Schaefer DJ: Abstract: 14.50 Epidemiology and survival of patients with hard palate melanoma: a population-based study. Plast Reconstr Surg Glob Open 5(1): 16, 2017.

2 Barker BF, Carpenter WM, Daniels TE, Kahn MA, Leider AS, Lozada-Nur F, Lynch DP, Melrose R, Merrell P, Morton T, Peters E, Regezi JA, Richards SD, Rick GM, Rohrer MD, Slater L, Stewart JC, Tomich CE, Vickers RA, Wood NK and Young SK: Oral mucosal melanomas: The WESTOP Banff workshop proceedings. Western Society of Teachers of Oral Pathology. Oral Surg Oral Med Oral Pathol Oral Radiol Endod 83: 672-679, 1997.

3 Garzino-Demo P, Fasolis M, Maggiore GM, Pagano M and Berrone S: Oral mucosal melanoma: a series of case reports. J Craniomaxillofac Surg 32: 251-257, 2004.

4 Patrick RJ, Fenske NA and Messina JL: Primary mucosal melanoma. J Am Acad Dermatol 56: 828-834, 2007.

5 Meleti M, Leemans CR, Mooi WJ, Vescovi P and van der Waal I: Oral malignant melanoma: A review of the literature. Oral Oncol 43: 116-121, 2007.

6 Meleti M, Leemans CR, Mooi WJ and Van der Waal I: Oral malignant melanoma: the Amsterdam experience. J Oral Maxillofac Surg 65: 2181-2186, 2007.

7 Tanaka N, Mimura M, Ogi K and Amagasa T: Primary malignant melanoma of the oral cavity: Assessment of outcome from the clinical records of 35 patients. Int J Oral Maxillofac Surg 33: 761-765, 2004.

8 Chang AE, Karnell LH and Mench HR: The national cancer data base report on cutaneous and noncutaneos melanoma: A summary of 84,836 cases from the past decade. The American College of Surgeons Commission on Cancer and the American Cancer Society. Cancer 83: 1664-1678, 1998.

9 Lopez-Graniel CM, Ochoa-Carrillo FJ and Meneses-Garcia A: Malignant melanoma of the oral cavity: Diagnosis and treatment experience in a Mexican population. Oral Oncol 35: 425-430, 1999.

10 Takagi M, Ishikawa G and Mori W: Primary malignant melanoma of the oral cavity in Japan. Cancer 34: 358-370, 1974.

11 Prasad ML, Patel SG and Busam KJ: Primary mucosal desmoplastic melanoma of the head and neck. Head Neck 26: 373-377, 2004.

12 Keller DS, Thomay AA, Gaughan J, Olszanski A, Wu H, Berger AC, Farma JM: Outcomes in patients with mucosal melanomas. J Surg Oncol 108: 516-520, 2013.

13 Patel SG, Prasad ML, Escrig M, Singh B, Shaha AR, Kraus DH, Boyle JO, Huvos AG, Busam K and Shah JP: Primary mucosal malignant melanoma of the head and neck. Head Neck 24: 247257, 2002.

14 Wushou A and Zhao YJ: The management and site-specific prognostic factors of primary oral mucosal malignant melanoma. J Craniofac Surg 26: 430-434, 2015.

15 Song H, Wu Y, Ren G, Guo W and Wang L: Prognostic factors of oral mucosal melanoma: Histopathological analysis in a retrospective cohort of 82 cases. Histopathology 67: 548-556, 2015. 
16 National Cancer Institute - Surveillance, Epidemiology, and End Results (SEER) Program: Overview of the SEER Program. Available at: https://seer.cancer.gov/about/overview.html Accessed August 13, 2018.

17 National Cancer Institute - Surveillance, Epidemiology, and End Results (SEER) Program: SEER*Stat Databases: November 2014 Submission. Available at: https://seer.cancer.gov/datasoftware/documentation/seerstat/nov2014/. Accessed May 23, 2016.

18 Patrick RJ, Fenske NA and Messina JL: Primary mucosal melanoma. J Am Acad Dermatol 56: 828-834, 2007.

19 Mihajlovic M, Vlajkovic S, Jovanovic P and Stefanovic V: Primary mucosal melanomas: A comprehensive review. Int $\mathbf{J}$ Clin Exp Pathol 5: 739-753, 2012.

20 Siegel R, Naishadham D and Jemal A: Cancer statistics, 2012. CA Cancer J Clin 62: 10-29, 2012.

21 McLaughlin CC, Wu XC, Jemal A, Martin HJ, Roche LM and Chen VW: Incidence of noncutaneous melanomas in the U.S Cancer 103: 1000-1007, 2005.

22 Simard EP, Ward EM, Siegel R and Jemal A: Cancers with increasing incidence trends in the United States: 1999 through 2008. CA Cancer J Clin 62: 118-128, 2012.

23 Chang AE, Karnell LH and Menck HR: The National Cancer Data Base report on cutaneous and noncutaneous melanoma. Cancer 83: 1664-1678, 1998.

24 Warszawik-Hendzel O, Słowińska M, Olszewska M and Rudnicka L: Melanoma of the oral cavity: Pathogenesis, dermoscopy, clinical features, staging and management. J Dermatol Case Rep 8: 60-66, 2014.

25 Tacastacas JD, Bray J, Cohen YK, Arbesman J, Kim J, Koon HB, Honda K, Cooper KD and Gerstenblith MR: Update on primary mucosal melanoma. J Am Acad Dermatol 71: 366-375, 2014.

26 Prasad ML, Jungbluth AA, Patel SG, Iversen K, HoshawWoodard S and Busam KJ: Expression and significance of cancer testis antigens in primary mucosal melanoma of the head and neck. Head Neck 26: 1053-1057, 2004.

27 Jethanamest D, Vila PM, Sikora AG and Morris LG: Predictors of survival in mucosal melanoma of the head and neck. Ann Surg Oncol 18: 2748-2756, 2011.
28 Bishop KD and Olszweski AJ: Epidemiology and survival outcomes of ocular and mucosal melanomas: A population-based analysis Int J Cancer 134: 2961-2971, 2014.

29 Manolidis S and Donald PJ: Malignant mucosal melanoma of the head and neck: Review of the literature and report of 14 patients. Cancer 80: 1373-1386, 1997.

30 Bachar G, Loh KS, O'Sullivan B, Goldstein D, Wood S, Brown $\mathrm{D}$ and Irish J: Mucosal melanomas of the head and neck: The Princess Margaret Hospital experience. Head Neck J Sci Spec 30: 1325-1331, 2008.

31 Koomen ER, de Vries E, van Kempen LC, van Akkooi AC, Guchelaar HJ, Louwman MW, Nijsten T and Coebergh JW: Epidemiology of extracutaneous melanoma in the Netherlands. Cancer Epidemiol Biomarkers Prev 19: 1453-1459, 2010.

32 Haiducu ML, Hinek A, Astanehe A, Lee TK and Kalia S: Extracutaneous melanoma epidemiology in British Columbia. Melanoma Res 24: 377-380, 2014.

33 Sun CZ, Chen YF, Jiang YE, Hu ZD, Yang AK and Song M: Treatment and prognosis of oral mucosal melanoma. Oral Oncol 48: 647-652, 2012.

34 Tanaka N, Mimura M, Kimijima Y and Amagasa T: Clinical investigation of amelanotic malignant melanoma in the oral region. J Oral Maxillofac Surg 62: 933-937, 2004.

35 Sortino-Rachou AM, Cancela Mde C, Voti L, Curado MP: Primary oral melanoma: Population-based incidence. Oral Oncol 45: 254-258, 2009.

36 Rapini RP, Golitz LE, Greer RO Jr, Krekorian EA and Poulson T: Primary malignant melanoma of the oral cavity. A review of 177 cases. Cancer 55: 1543-1551, 1985.

37 Tomicic J and Wanebo HJ: Mucosal melanomas. Surg Clin North Am 83: 237-252, 2003.

38 Bentzen SM, Overgaard J and Thames HD: Clinical radiobiology of malignant melanoma. Radiother Oncol 16: 169-182, 1989.

Received August 23, 2018

Revised September 5, 2018

Accepted September 6, 2018 